\title{
The Molecular Mechanism for Differentiation Therapy of Malignant Glioma
}

\author{
Wenbo Zhu and Guangmei Yan \\ Zhongshan School of Medicine, Sun Yat-sen University \\ People's Republic of China
}

\section{Introduction}

Gliomas are the most common malignant cancer affecting the CNS, accounting for $60 \%$ of primary brain tumors (DeAngelis, 2001; Yiu\&He, 2006). The majority of gliomas in adults are highly malignant with a poor prognosis, in particular with high-grade tumors such as glioblastoma multiforme. Current therapy with surgery, radiation, and chemotherapy rarely, if ever, cures the disease and infrequently prolongs life for 1 year (Curran et al., 1993; Bao et al., 2006). Additional considerations focus on developing novel modalities to increase anti-glioma effects and decrease side-effects.

Differentiation therapy, using agents that modify cancer cell differentiation, has shown promise in the spectrum of agents used against tumors (Leszczyniecka et al., 2001). Wang and Chen demonstrated the clinical application for differentiation therapy by introducing all-trans-retinoic acid to clinical use for the treatment of acute promyelocytic leukemia (APL) (Huang et al., 1988; Wang\&Chen, 2000). Notably, the inorganic toxicant arsenic trioxide (As2O3), a well known environmental carcinogen, has been also proven to be an effective drug in the treatment of APL patients by triggering apoptosis and differentiation of APL cells in a dose-dependent manner (Shen et al., 1997; Kinjo et al., 2000). Such excellent effects, however, were not reproduced in other hematological and, particularly, solid tumors. Differentiation agents for malignant gliomas remain a real challenge.

In this chapter, we base on our research and mainly discuss proteins or molecules capable of inducing differentiation via targeting cAMP/cAMP-dependent protein kinase A (PKA)

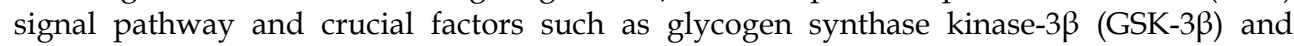
hypoxia-inducible factor-1a (HIF-1a) determining the efficiency of these drugs. Although agents for differentiation therapy have wide application prospect, their real therapeutic potentiality remains to be further realized.

\section{The molecular mechanism for differentiation therapy of malignant glioma}

\subsection{CAMP/PKA signaling activators induce malignant glioma cell differentiation}

cAMP/PKA signaling has been reported to play important roles in multiple physiological processes, including growth, differentiation, gene regulation, and apoptosis (Walsh\&Van Patten, 1994). Disruption of the PKA catalytic subunit causes destabilization of the diploid cell cycle, and the cells start meiosis under conditions repressive for wild-type meiosis (Maeda et al., 1994). Ample evidences indicate that cAMP-elevating stimuli such as N- 
substituted cAMP analogues and cAMP-increasing reagents can induce cell differentiation in gliomas (Takanaga et al., 2004; Van Kolen\&Slegers, 2004).

\subsubsection{Biotoxin-cholera toxin}

Cholera toxin is the major virulent factor of Vibrio cholerae and is the most recognizable enterotoxin causing diarrhea, the disease second only to cardiovascular disease as causes of death (Goodman\&Segreti, 1999). Cholera toxin catalyzes ADP-ribosylation of Gs protein and results in accumulation of cellular cAMP (Moss\&Vaughan, 1979; Guerrant et al., 1994). Guerrant et al. reports that active whole cholera toxin, but not inactive choleragenoid, produces elevation of cAMP and parallel morphological changes in $\mathrm{CHO}$ cells (Guerrant et al., 1974). Ganglioside GM1 reaction with the B subunit of cholera toxin is reported to induce neuron-like differentiation of PC12 and neuroblastoma cells (Masco et al., 1991; Kimura et al., 2001). All of the findings mentioned above reveal the potential of cholera toxin, a kind of biotoxin, in the differentiation induction of tumor cells.

In Li's study (Li et al., 2007), rat malignant glioma cell line C6 cells in conjunction with primary cultured human glioma cells, which are much more clinically relevant, are used to characterize the effect of cholera toxin on the key malignant phenotypes of malignant glioma cells to see whether it induces differentiation in them. Cholera toxin triggers cell transformation indicative of the cells' differentiation into a more mature astrocytic state (Figure 1a and 1c). This differentiation potential is further confirmed by an increased

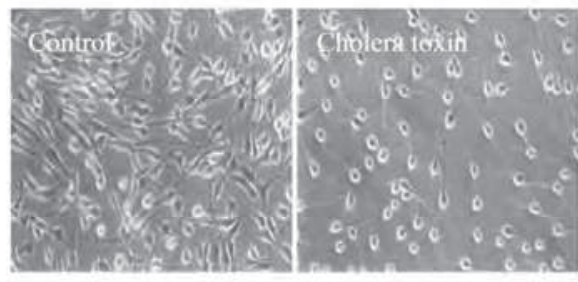

(a) Morphological transformation induced by cholera toxin in rat glioma cell line $\mathrm{C} 6$ cells. (Original magnification: $\times 200$.)
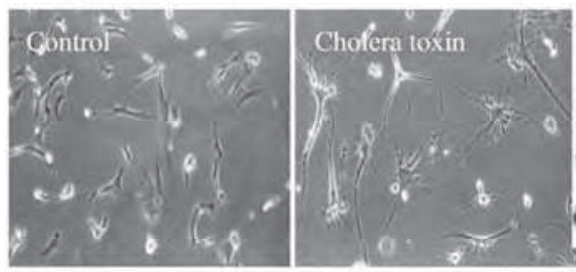

(c) Morphological transformation induced by cholera toxin in primary cultured human glioma cells. (Original magnification: $\times 200$.)

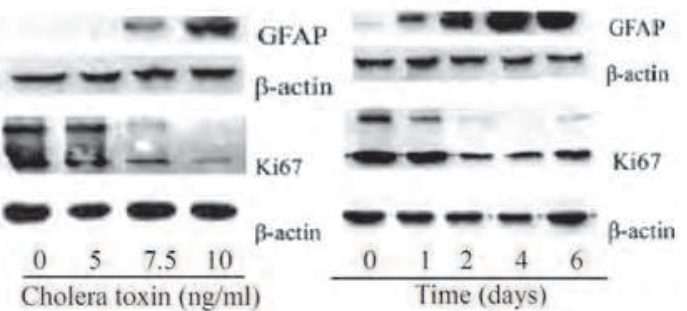

(b) Concentration- and time-dependent effect of cholera toxin on GFAP and $\mathrm{Ki}-67$ expression in C6 cells.

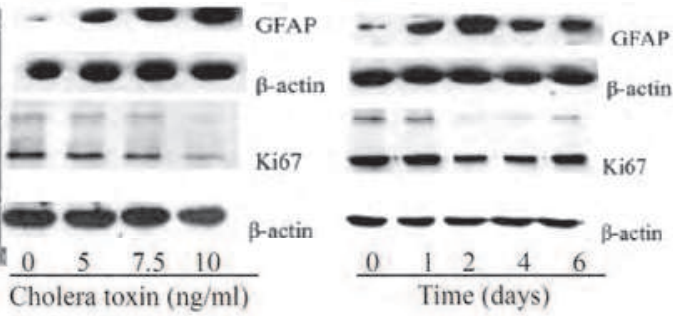

(d) Concentration- and time-dependent effect of cholera toxin on GFAP and $\mathrm{Ki}-67$ expression in primary cultured human glioma cells.

Fig. 1. Morphological transformation, GFAP and Ki-67 expression induced by cholera toxin in rat glioma cell line C6 cells and primary cultured human glioma cells. 
expression of GFAP, a 50-kDa type III intermediate filament protein considered to be a reliable differentiation marker of normal astrocytes (Roymans et al., 2001), and a lowered amount of Ki-67 protein (Figure $1 \mathrm{~b}$ and $1 \mathrm{~d}$ ). The Ki-67 antigen presents during all active phases of the cell cycle but is absent from resting cells exclusively in the nuclei of cycling cells; the defined period of nuclear expression makes it a reliable marker of malignant proliferating cells (Schluter et al., 1993; Shachaf et al., 2004). In further experiments (Shu et al., 2011), the cholera toxin-induced GFAP expression is proved to be mediated by an oncogenic pathway interleukin-6/janus kinase 2/signal transducer and activator of transcription 3 (IL-6/JAK2/STAT3) cascade, implies that a survival-promoting signal may also play a differentiation-supporting role in malignant gliomas (Figure 2). However, the B subunit of cholera toxin (choleragenoid) at a dose of $10 \mathrm{ng} / \mathrm{ml}$ and even $10 \mu \mathrm{g} / \mathrm{ml}$ does not cause any alterations on cell morphology, GFAP expression and proliferation in C6 glioma cells (Figure 3). A mechanism that cholera toxin specifically activates ganglioside GM1 and induces differentiation in C6 glioma cells is therefore eradicated.

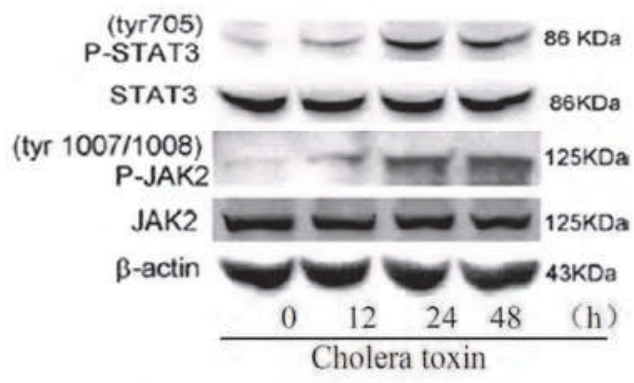

(a) Time-dependent effects of cholera toxin on phosphorylation of STAT3 (tyr705) and JAK2 (tyr1007/1008).

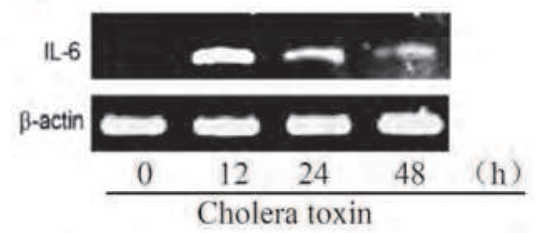

(c) Time-dependent effects of cholera toxin on IL-6 mRNA level.

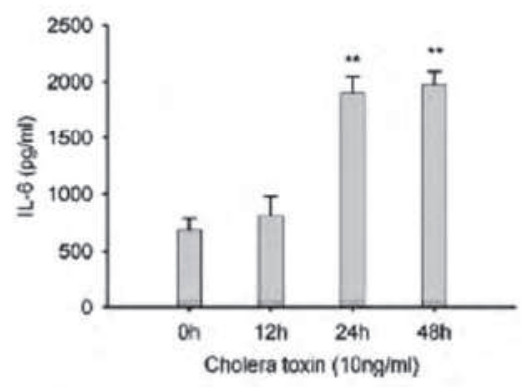

(b) Time-dependent effects of cholera toxin on IL-6 protein expression.

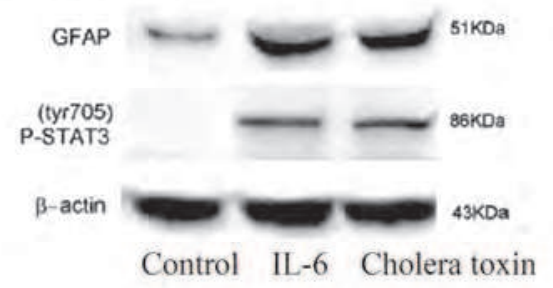

(d) IL-6 induces GFAP expression.

Fig. 2. Activation of IL-6/JAK2/STAT3 contributes to GFAP induction during the cholera toxin-induced differentiation in C6 glioma cells.

The regulation of cell proliferation and terminal differentiation is a critical aspect of normal development and homeostasis, but is frequently disturbed during tumorigenesis. Cell proliferation and differentiation are specifically controlled in the G1 phase and the G1/S phase transition in the cell cycle (Nurse, 2000). In differentiation triggered by cholera toxin, cellular proliferation inhibition is observed but not significant cell death and accumulation 
of cells in the G0/G1 phase of the cell cycle at multiple points within the machinery governing the G1/S transition is concurrent (Figure 4a-c and Table 1). The expression of G1 control proteins cyclin D1 and Cdk2 is down-regulated and associated with profound increased p21Cip1 and p27Kip1 protein levels (Figure 4d). Cyclin D1 is a critical regulator involved in cell-cycle progression through the G1 phase into the $S$ phase, thereby contributing to cell proliferation. Cyclin D1 expression is significantly correlated with the degree of malignancy, invasion and prognosis of patients in a variety of human carcinomas, including glioma (Arato-Ohshima\&Sawa, 1999; Lamb et al., 2003). The Cdk inhibitors p21 ${ }^{\text {Cip1 }}$ and p27Kip1 play an important role in mediating growth arrest and are thought to function as brakes of the cell cycle (Sherr\&Roberts, 1999). The downregulation of cyclin D1 and overexpression of $\mathrm{p}^{2} \mathrm{C}^{\mathrm{Cip} 1}$ and $\mathrm{p} 2 \mathrm{~K}^{\mathrm{Kip} 1}$ might therefore be a pivotal candidate for the perturbed cell-cycle progression and differentiation induced by cholera toxin.
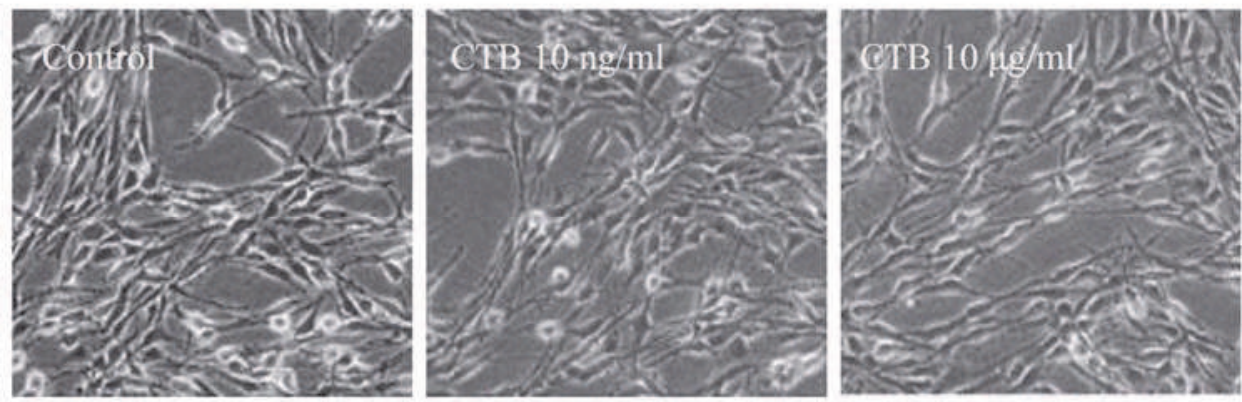

(a) Morphological transformation induced by the B subunit of cholera toxin (CTB) in C6 cells. (Original magnification: $\times 200$.)
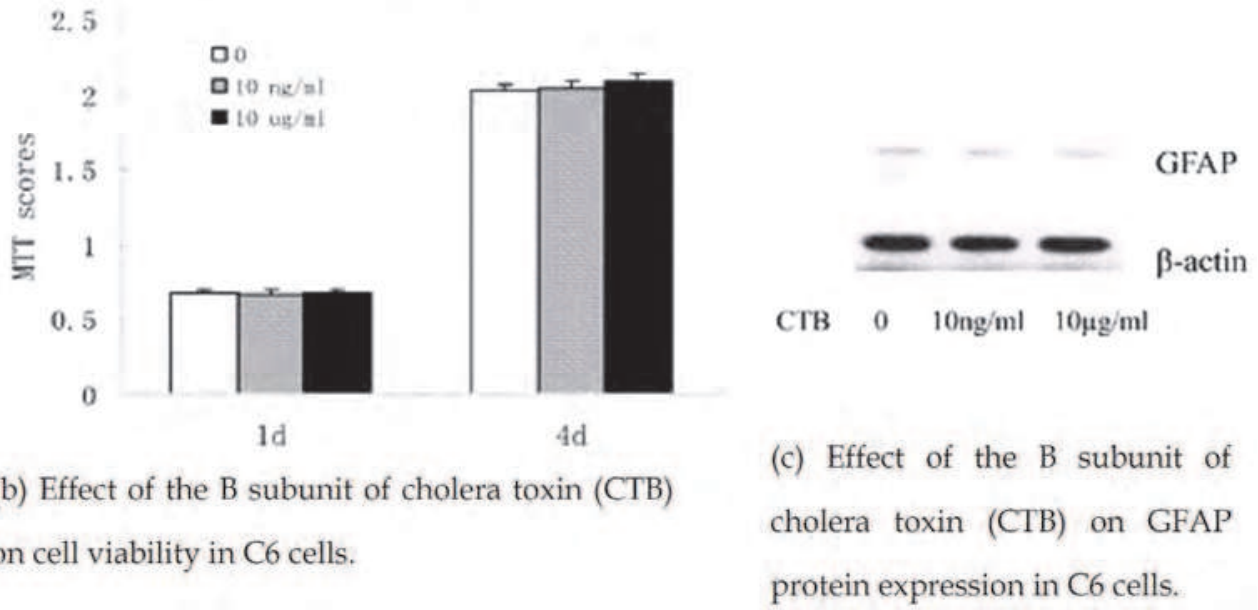

Fig. 3. The B subunit of cholera toxin does not cause any alterations on cell morphology, GFAP expression, and proliferation in C6 glioma cells. 


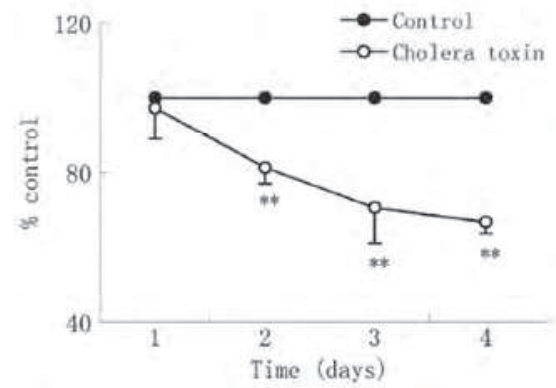

(a) Time-dependent effect of cholera toxin on cell viability in C6 cells.

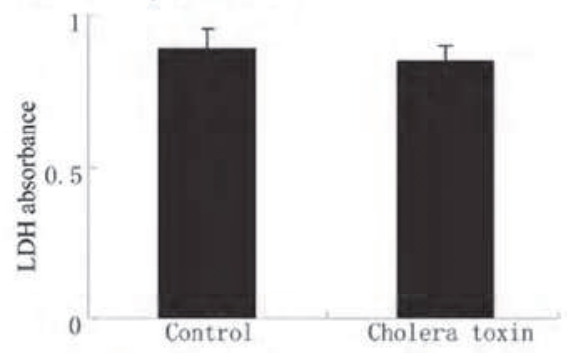

(c) Effect of cholera toxin on LDH release in $\mathrm{C} 6$ cells.

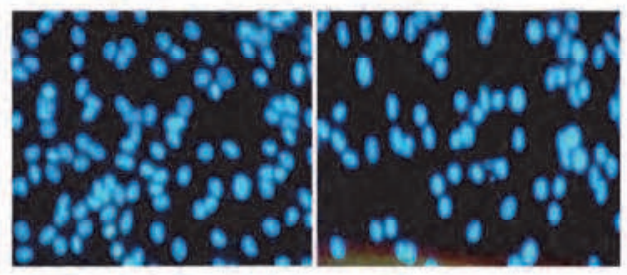

(b) Effect of cholera toxin on cell apoptosis in C6 cells (Hoechst 33258 staining).

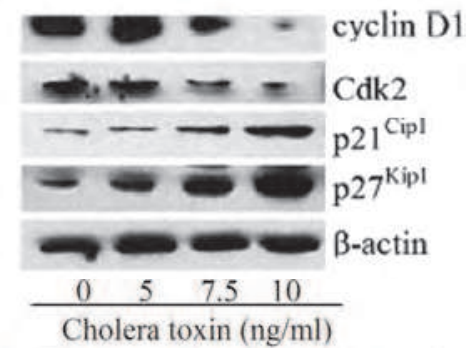

(d) Effect of cholera toxin on cell-cycle regulatory molecules in C6 cells.

Fig. 4. Cholera toxin inhibits cell proliferation and alters the protein expressions of cell-cycle regulatory molecules in C6 glioma cells.

\begin{tabular}{lccccc} 
& \multicolumn{2}{c}{ C6 glioma cells } & & \multicolumn{3}{c}{ Human primary glioma cells } \\
\cline { 2 - 3 } \cline { 5 - 6 } Groups & G0/G1 & S & & G0/G1 & S \\
\hline Control & $63.6 \pm 7.4$ & $27.7 \pm 5.9$ & & $51.5 \pm 11.8$ & $36.0 \pm 8.2$ \\
Cholera toxin & $88.2 \pm 6.8^{*}$ & $7.9 \pm 3.9^{* *}$ & & $81.3 \pm 3.1 * *$ & $7.7 \pm 2.9 * *$ \\
\hline
\end{tabular}

Results are expressed as means $\pm \mathrm{SD}(\mathrm{n}=3$ ) for control and cholera toxin groups. *, $\mathrm{p}<0.05 ;{ }^{* *}, \mathrm{p}<0.01$ compared with control, respectively.

Table 1. Cholera toxin causes a G0/G1-phase cell cycle arrest in C6 and human primary glioma cells.

One of the potential downstream signaling targets of PKA is the CREB protein, an inducible transcription factor. Phosphorylation of Ser-133 is a critical event in CREB activation, leading to an increase of transcriptional activation by the recruitment of additional coactivators. The phosphorylation of CREB by PKA-mediated cAMP-dependent signaling 
cascade responds to a variety of external signals and appears to play crucial roles in differentiation and neurite outgrowth in multiple cell lines (Masson et al., 1993; Impey et al., 2004; Sato et al., 2006). Cells from transgenic mice expressing a dominant-negative form of CREB show a profound proliferative defect and G1 cell-cycle arrest in response to a number of different activation signals (Barton et al., 1996). It remains to be explored, however, whether PKA/CREB signaling participates in the differentiation of malignant glioma cells. In cholera toxin-treated glioma cells, a cholera toxin-induced cAMP increase is able to trigger the activation of downstream effectors, as evidenced by PKA activation and CREB transcription factor phosphorylation (Figure 5a). In addition, the essential role of PKA
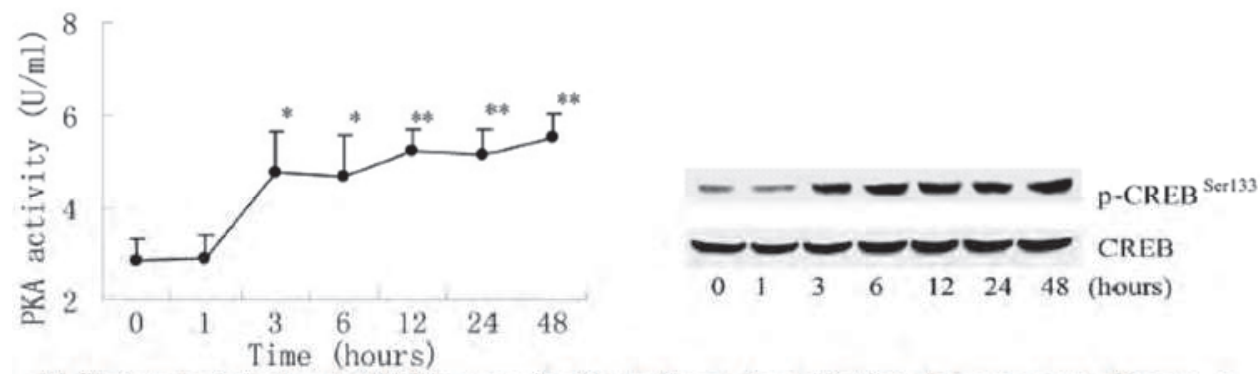

(a) Cholera toxin-induced cAMP increase is able to trigger the activation of downstream effectors, as evidenced by PKA activation and CREB transcription factor phosphorylation.
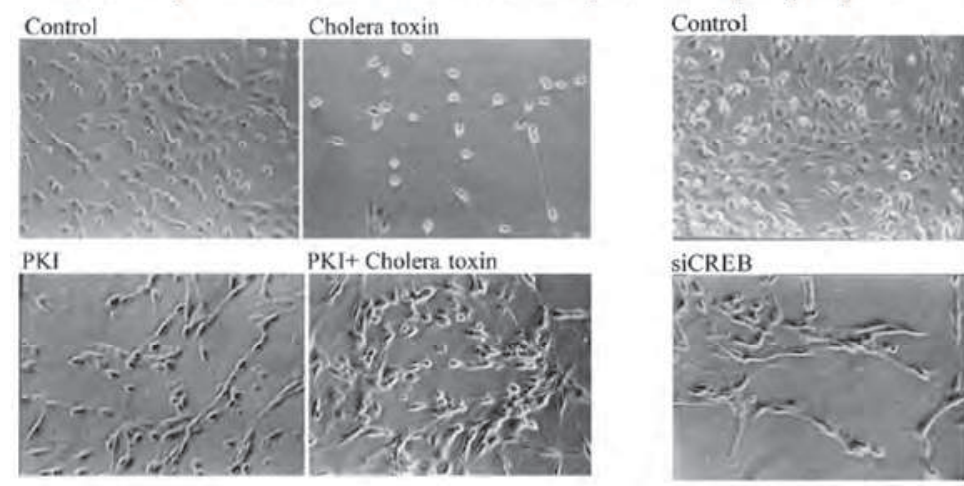

Cholera toxin
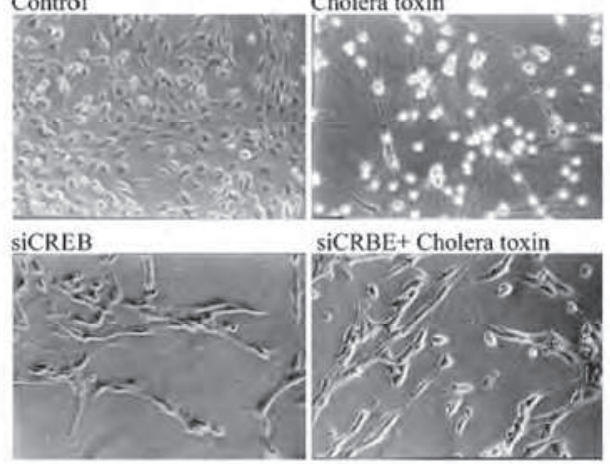

siCRBE+ Cholera toxin

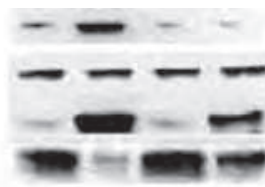

p-CREB ${ }^{\text {Serl33 }}$

CREB

GFAP

cyclin DI

Cholera toxin -

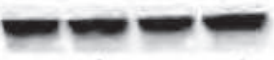

$\beta$-actin

(b) PKA activity mediates for cholera toxin-induced differentiation in $\mathrm{C} 6$ cells.

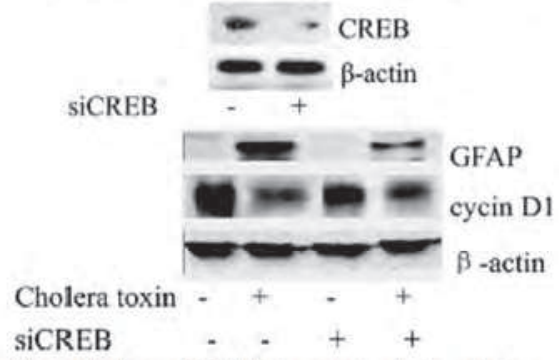

(c) Up-regulation of CREB is required for cholera toxin-induced differentiation in $\mathrm{C} 6$ cells

Fig. 5. Cholera toxin-induced differentiation is inhibited by PKI or depletion of CREB. 
activation in the cholera toxin-induced differentiation process is supported by experiments showing that differentiation is impaired if PKA activity is inhibited by PKI added before the differentiating agent cholera toxin or depletion of CREB by siRNA (Figure $5 b$ and $5 c$ ). These data indicate that differentiation triggered by cholera toxin is effected through the PKA/CREB pathway and suggest the requisite role of PKA and transcription factor CREB for cholera toxin-induced differentiation.

In conclusion, cholera toxin might be an astrocytic differentiation-inducing agent in rat C6 and primary cultured human glioma cells of intensified therapeutic interest in the treatment of glioma. This effect may be caused by G1 arrest in the cell cycle ascribed to the restrain of cyclin D1 and Cdk2 activities by augmented expression of $\mathrm{p} 21^{\mathrm{Cip} 1}$ and $\mathrm{p} 2 \mathrm{7Kip}^{1}$ proteins. Of the various possibilities for cholera toxin-induced differentiation, elevated PKA/CREB signaling pathway represents a plausible candidate. Significantly, cholera toxin, the traditional bacterial toxin, may be a novel agent with substantial differentiation potential in the therapy of malignant glioma. Future studies, however, should extend these findings to in vivo tumor models.

\subsubsection{Forskolin and other PKA activators}

Forskolin, a diterpene extracted from the roots of the plant Coleus forskohlii, directly activates adenylate cyclase (AC) and catalyzes synthesis of cAMP from ATP to activate PKA. Accumulating evidences have reported that forskolin induces the differentiation of human monoblast U937 cells, neurocytoma cells and neuroblastoma $x$ rat glioma cell line NG108-15 cells via elevating cAMP (Ammer\&Schulz, 1997; Brodsky et al., 1998; Kim et al., 2004), suggesting forskolin to be a potential candidate of differentiation inducing agents for glioma. In accordance with previous reports, forskolin represses cell growth via cell cycle arrest in the G0/G1 phase and induces cell differentiation characteristic with elongated processes and restoration of GFAP expression when administrated to malignant glioma C6 cells (Figure 6a and 6b) (Lu et al., 2009; He et al., 2011). In mechanisms, forskolin promotes C6 cell differentiation via regulating the transcription and proteolysis of cyclin D1, and maintenance of low cyclin D1 expression is required for its effects on differentiation as demonstrated by gain and loss of function studies (Figure $6 \mathrm{c}$ and $6 \mathrm{~d}$ ). All the information supports the notion that forskolin can be developed into a candidate for the future in differentiation therapy of glioma, and cyclin D1 is a promising target for pro-differentiation strategy.

All data mentioned above also indicates that other cAMP/PKA signaling activators should have the same potential to induce cell differentiation and proliferation inhibition. Data in Figure 7 show that db-cAMP mimics forskolin's differentiation effects of cholera toxin on cell morphology, GFAP expression, cell proliferation, and cell-cycle distributions in C6 glioma cells.

\subsection{GSK-3 $\beta$ controls differentiation of malignant glioma cells}

GSK-3 is an evolutionary conserved, ubiquitous serine/threonine kinase that is highly enriched in the brain and consists of 2 distinct isoforms, $a$ and $\beta$, in mammals (Woodgett, 1991). One of the most notable qualities of GSK-3 is the vast number of signaling pathways that converge on this enzyme and subsequently an even greater number of biological targets (Cohen\&Frame, 2001; Jope\&Johnson, 2004). Numerous studies have indicated that GSK-3 is involved in key functions of the brain and is associated with dysfunction in multiple 
neurological diseases (Grimes\&Jope, 2001). More recent studies indicate a role for GSK-3 in the control of neoplastic transformation and tumor development, suggesting that GSK-3 is a potential therapeutic target in human cancers. However, most attention has focused on the $\beta$-isoform of GSK-3 and the exact role of GSK-3 $\beta$ in malignancies remains highly controversial due to the conflicting results from different tumor models. Although some studies found that GSK-3 $\beta$ is a part of a tumor suppressor complex that phosphorylates the oncoprotein $\beta$-catenin and that GSK-3 $\beta$ inactivation could possibly lead to tumor promotion (Hinoi et al., 2000; Rask et al., 2003), other studies have shown that inhibition of GSK-3 $\beta$ suppresses cancer cell proliferation and induces apoptosis by abrogating nuclear factor NF-kB mediated gene transcription (Ougolkov et al., 2005; Ougolkov et al., 2007). In addition, the vast majority of research on GSK-3 $\beta$ has been focused on the aspects of proliferation and apoptosis, and little is known about its possible role involved in the process of cancer cell differentiation. In differentiation-sensitive C6 and U87-MG malignant glioma cells, intensive GSK-3 $\beta$ is highly expressed and activated during the cholera toxin-induced differentiation, whereas the GSK-3 $\alpha$ activity remains stable. In differentiation-resistant U251 and T98G glioma cells, GSK-3 $\beta$ is lowly expressed (Figure $8 a$ ). Inhibition of GSK-3 $\beta$ activity or knockdown of its expression by small interfering RNA (siRNA) suppresses this differentiation (Figure $8 b$ ), whereas constitutively active S9A-GSK-3 $\beta$ initiates robust differentiation in differentiationresistant U251 glioma cells (Figure 8c). These results indicate that GSK-3 $\beta$ overexpression and activation possibly is a contributory event in the process of cellular differentiation in malignant gliomas. In addition, ubiquitin/proteasome-dependent degradation is identified the major pathway responsible for cyclin D1 reduction and sequential differentiation. By further experiments, GSK-3 $\beta$ is confirmed to regulate differentiation by triggering cyclin D1 translocation and degradation (Figure 9).

To extend these findings to clinical malignant gliomas, a series of 10 primary cell cultures grown from 7 Grade III and 3 Grade IV malignant astrocytoma explants are further prepared. Exposure to the differentiation agent cholera toxin also results in differentiated characteristics with a stellar shape with filamentous processes and increased GFAP expression in all the primary cultures examined (Figure 10a). Furthermore, the phosphorylated form of GSK-3 $\beta$ shows the same alteration panel as in the rat C6 cell line and GSK-3 $\beta$ inhibitors $\mathrm{LiCl}$ and SB216732 could block the increased GFAP and decreased PCNA levels induced by differentiation agent cholera toxin (Figure 10b). These results confirm the findings in C6 cells and, moreover, suggest a general correlation of GSK-3 $\beta$ activity with differentiation in malignant glioma cells.

To further confirm the possibility that GSK-3 $\beta$ expression is associated with sensitivity to differentiation therapy, GSK-3 $\beta$ expression in human glioma tissue samples (WHO Grade III and IV) is examined by immunohistochemical staining. Tissues are scored on the basis of the percentage of GSK-3 $\beta$-positive tumor cells. As shown in Figure 10c, overexpression of GSK$3 \beta$ is observed frequently in the cytoplasm of tumor cells (representative immunostaining image from Grade IV malignant glioma tissues), whereas weak expression only is observed in the cytoplasm of cells from normal brain. p-GSK-3 $\beta^{\mathrm{Y} 216}$ that represents the active kinase form of GSK-3 $\beta$ is also detected to assess the activation state of the protein. Figure 10c shows a higher expression of $\mathrm{p}-\mathrm{GSK}-3 \beta^{\mathrm{Y} 216}$ in malignant gliomas compared with normal brain tissues (representative image from Grade IV malignant glioma tissues). The immunohistochemical results of GSK-3 $\beta$ expression and its Y216 phosphorylation in patients are summarized in Figure 10d. Together, it is likely that overexpression of active GSK-3 $\beta$ is a pathological characteristic of clinical malignant gliomas, which are sensitive to the induced-differentiation. 


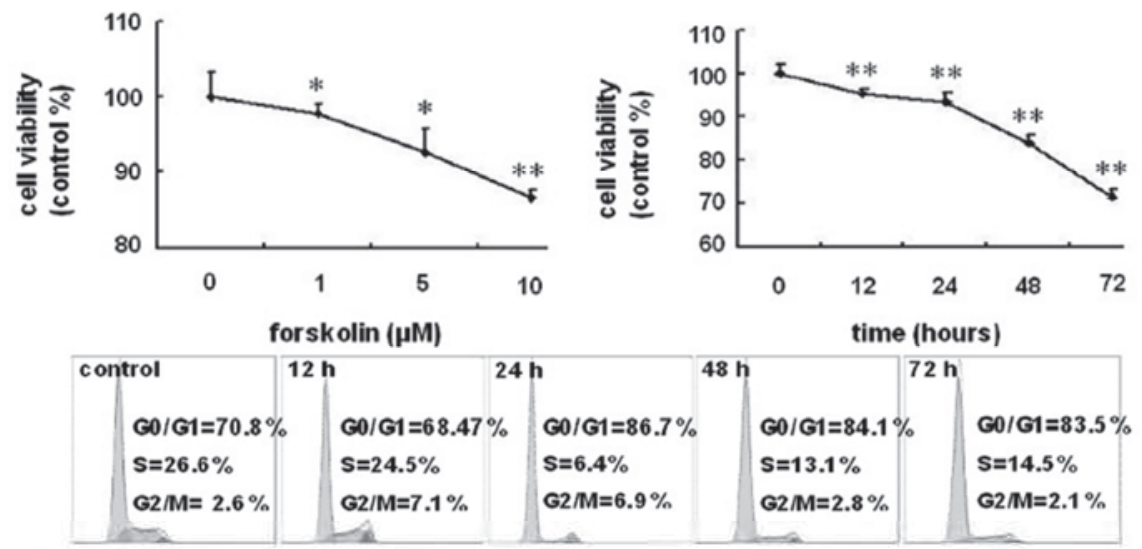

(a) Forskolin inhibits cell proliferation and induces G0/G1-phase cell cycle arrest in C6 cells.
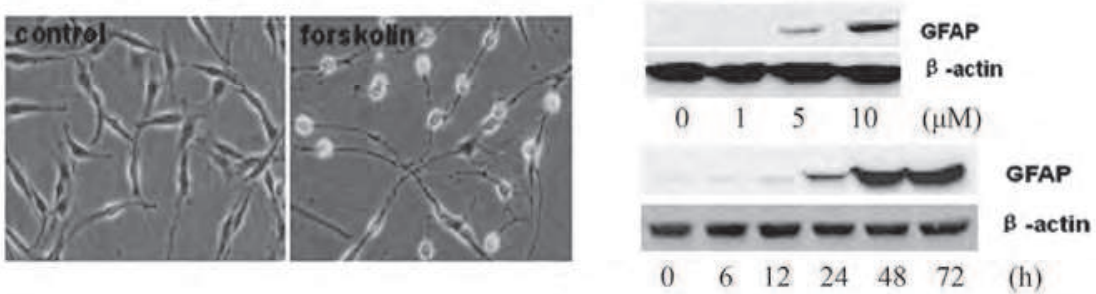

(b) Forskolin induces morphological transformation into astrocytic state and upregulation of GFAP protein expression in $\mathrm{C} 6$ cells.
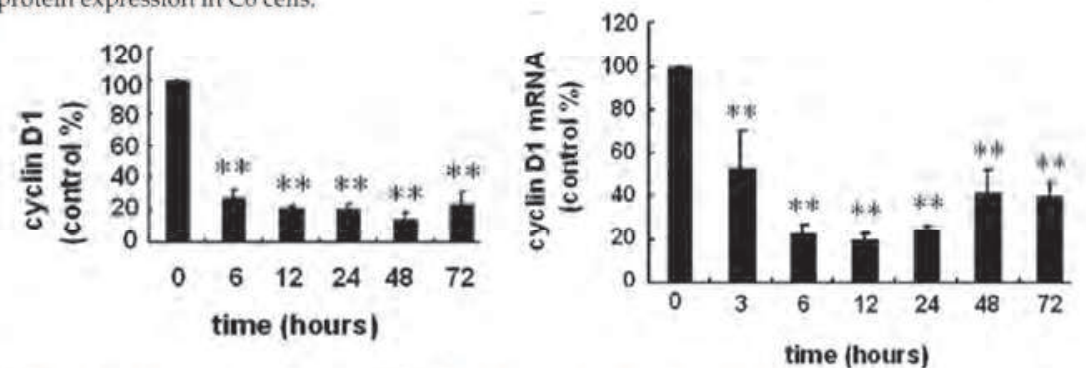

(c) Forskolin decreases the protein and mRNA levels of cyclin D1 in C6 cells.

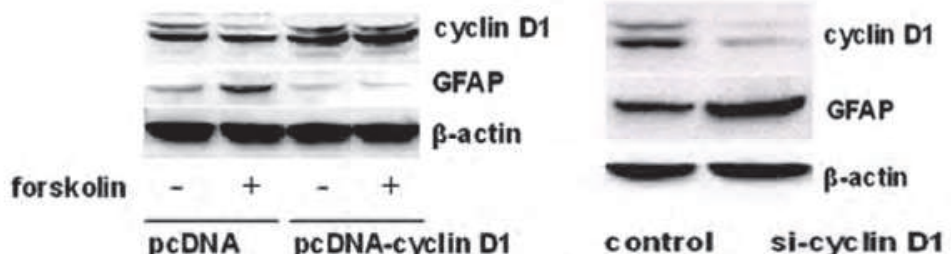

(d) Cyclin D1 down-regulation is requisite for forskolin-induced differentiation in C6 glioma cells.

Fig. 6. Forskolin induces differetiation via downregulation of cyclin D1. 

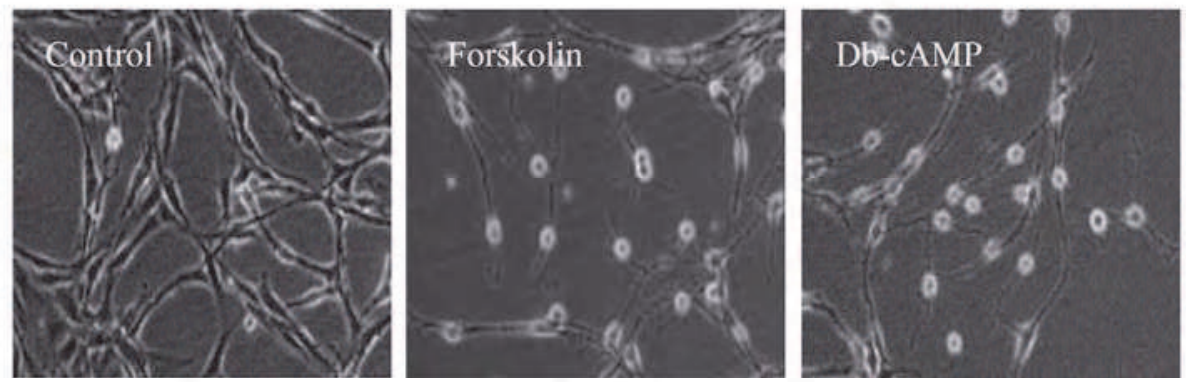

(a) Morphological transformation induced by forskolin and db-cAMP in C6 cells. (Original magnification: $\times 200$.)
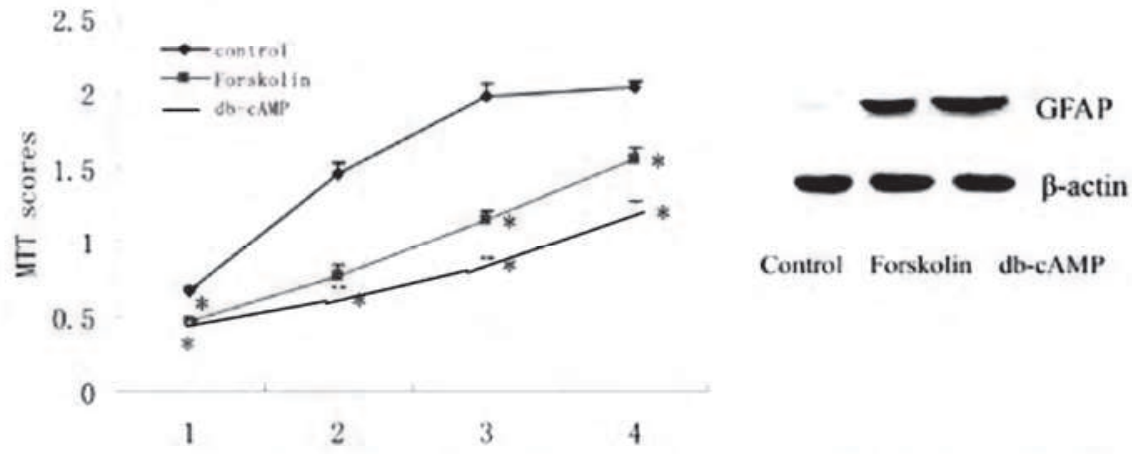

Control Forskolin db-cAMP

(b) Forskolin and db-cAMP induce cell proliferation inhibition and upregulation of GFAP protein expression in C6 cells.

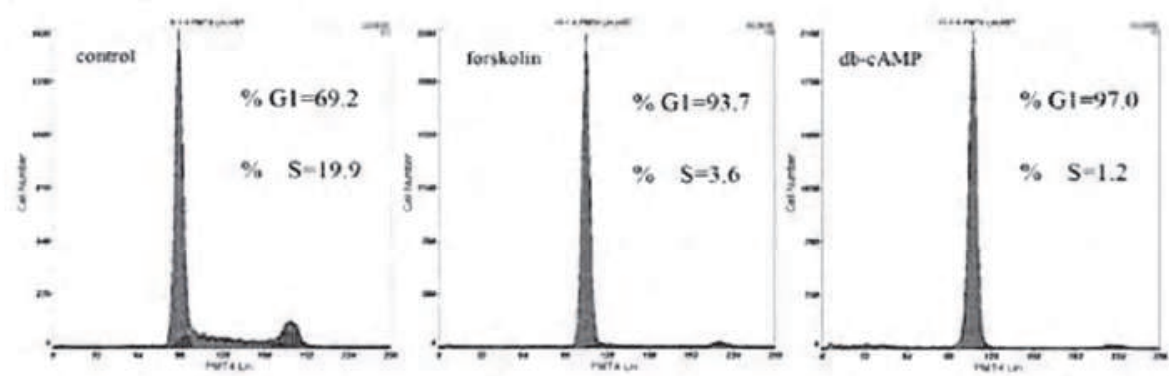

(c) Forskolin and db-cAMP induce G0/G1-phase cell cycle arrest in C6 cells.

Fig. 7. Forskolin and db-cAMP induce cell proliferation inhibition and cell differentation in C6 glioma cells. 


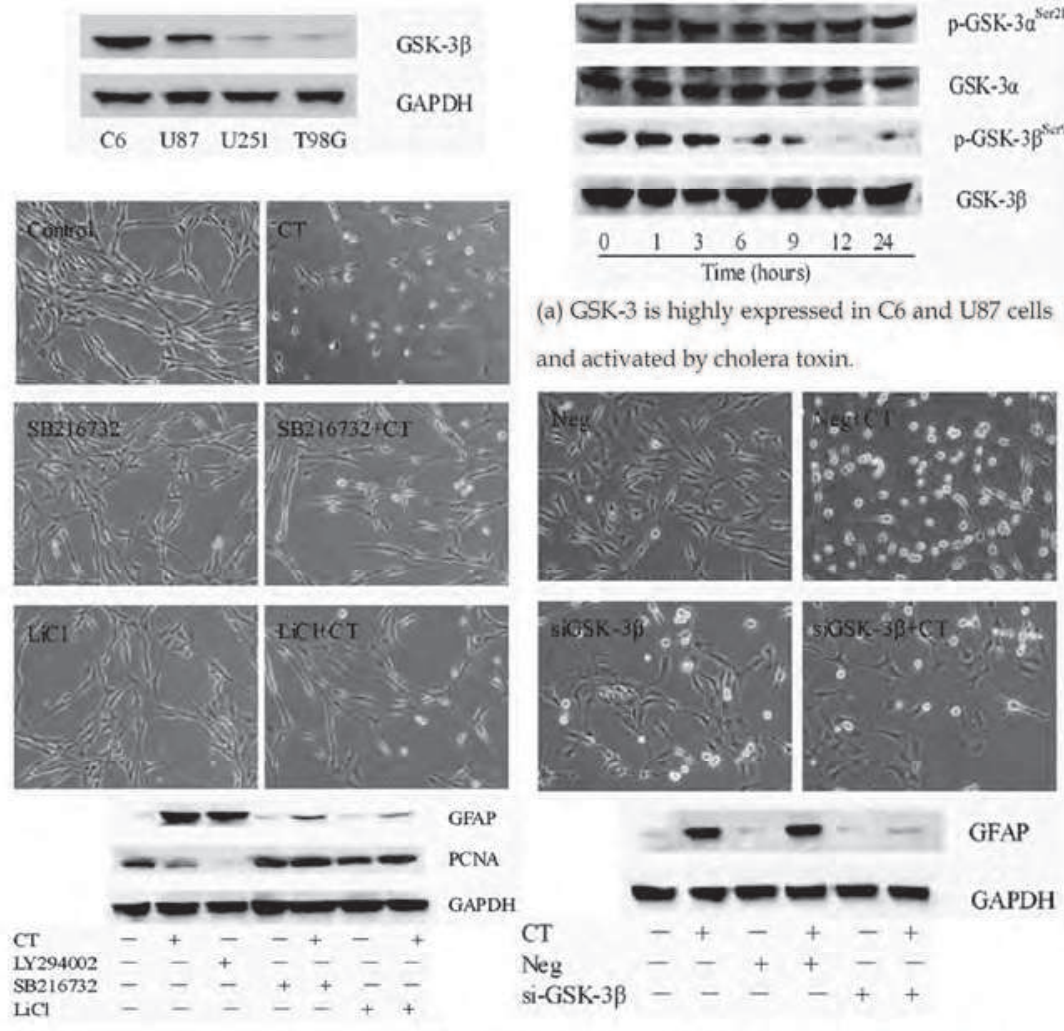

(b) Inhibition of GSK-3 $\beta$ activity or knockdown of its expression by small interfering RNA (siRNA) suppresses cholera toxin (CT)-induced differentiation.
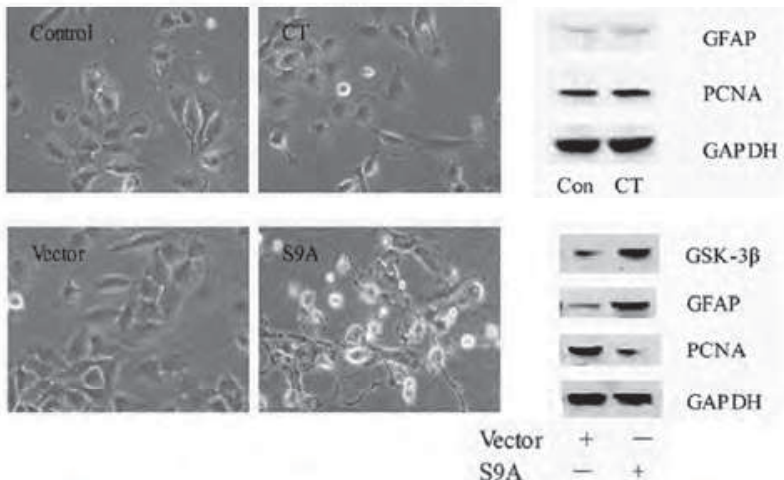

(c) Constitutively active S9A-GSK-3 3 initiates robust differentiation in differentiation-resistant U251 glioma cells.

Fig. 8. GSK-3 $\beta$ may be a determinant of cellular differetiation in malignant tumor as a pathological characteristic of differentiation-sensitive glioma cells. 


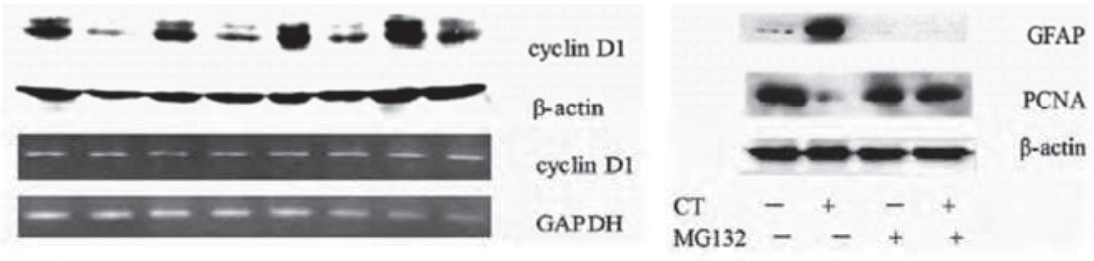

(a) Cholera toxin downregulates the protein level of cyclin D1 but not mRNA level and upregulation of GFAP and downregulation of PCNA induced by cholera toxin are attenuated by proteasome inhibitor MG132.

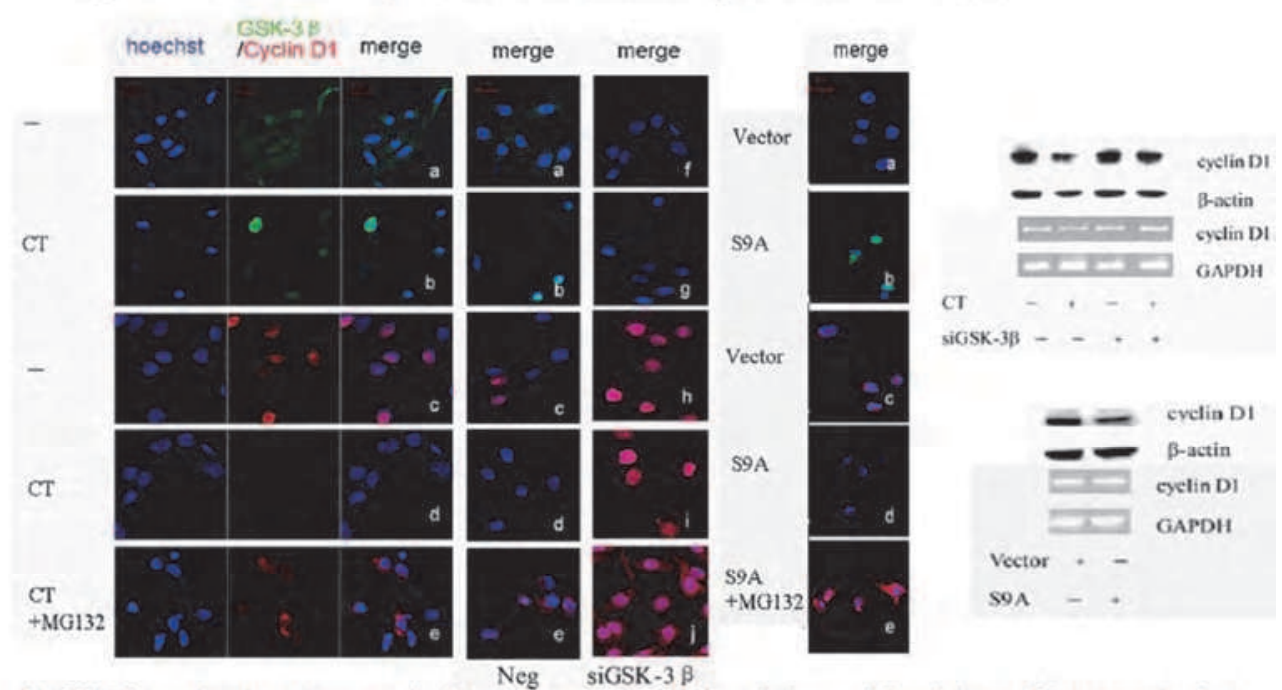

(b) GSK-3 $\beta$ translocation triggers cyclin D1 nuclear export and degradation, and knockdown of its expression by small interfering RNA (siRNA) suppresses this effect while constitutively active S9A-GSK-3 $\beta$ initiates this effect in differentiation-resistant U251 glioma cells.

Fig. 9. GSK-3 $\beta$ regulates differentiation by triggering cyclin D1 translocation and degradation. 


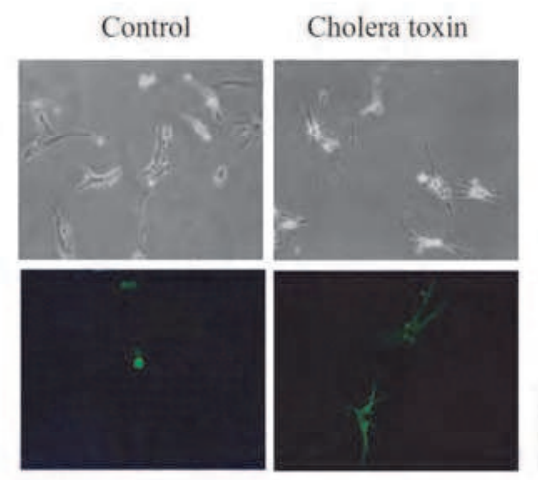

(a) Morphology and GFAP immunofluorescence in human primary cultured malignant glioma cells treated by cholera toxin.

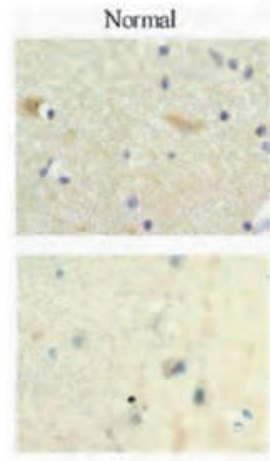

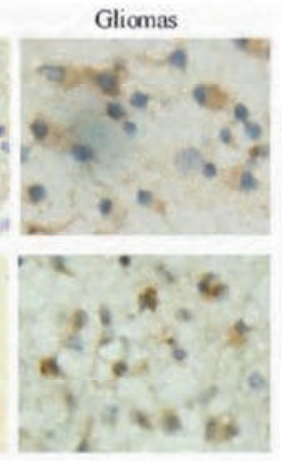

(c)

and

p-GSK-3 $3 \beta^{\text {r216 }}$

immunocytochemistry of stained sections from representative tissues of primary gliomas and normal brains.

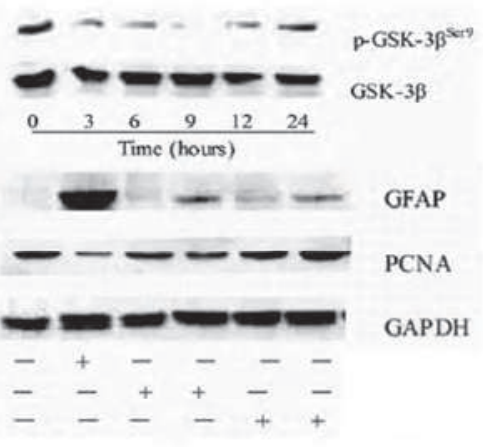

(b) Immunoblot of p-GSK-3 $\beta^{\text {ser }}$ and GSK-3 $\beta$ levels in cholera toxin $(\mathrm{CT})$-treated human primary cultured malignant glioma cells and GSK-3 $\beta$ inhibitors $\mathrm{LiCl}$ and SB216732 block the increased GFAP and decreased PCNA levels induced by cholera toxin.

GSK-3B

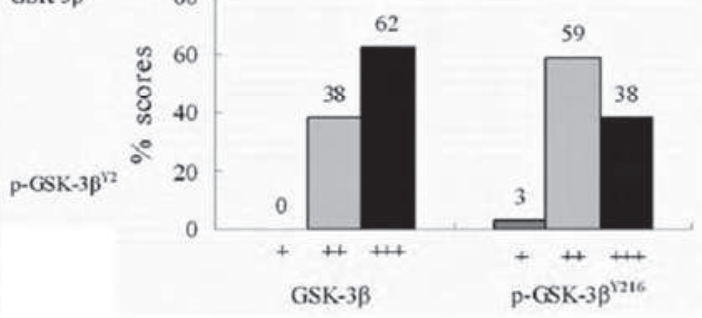

(d) Percentage of patients with malignant gliomas in

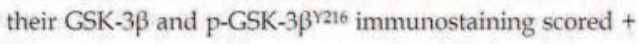
(positive staining for $<10 \%$ ), ++ (positive staining for $10-60 \%$ ), or +++ (positive staining for $>60 \%$ )

Fig. 10. Expression and phosphorylation of GSK-3 $\beta$ in primary human malignant gliomas.

In summary, GSK-3 $\beta$ initiates resistant glioma cells susceptible to differentiation and loss of GSK-3 $\beta$ activity interrupts cyclin D1 proteolysis necessary for the astrocytic differentiation of malignant glioma cells. These data provide strong evidence that GSK-3 $\beta$ acts as a tumor suppressor to induce cellular differentiation, and thus suppresses tumor development. As a pathological characteristic of differentiation-sensitive glioma cells, GSK-3 $\beta$ may be a novel therapeutic target and a determinant of cellular differentiation in malignant tumors. The data also show that GSK-3 $\alpha$ and GSK-3 $\beta$ have distinct biological roles, as the former is not involved in the differentiation-inducing mechanism of cholera toxin in malignant gliomas. 


\subsection{HIF-1a blocks differentiation of malignant gliomas}

Solid tumors frequently develop in regions with hypoxia because of an imbalance in oxygen supply and consumption. Recent reports indicate that hypoxic microenvironments contribute to cancer progression by activating adaptive transcriptional programs that promote cell survival, motility and tumor angiogenesis (Harris, 2002; Pouyssegur et al., 2006). Histopathological analyses frequently reveal the spatial overlap of hypoxia and dedifferentiation within solid tumors, suggesting the role of hypoxia in tumor cell differentiation (Jogi et al., 2002; Helczynska et al., 2003). However, it is unclear whether hypoxia plays a causal role in this relationship.

Cells within hypoxic regions adapt to this environment by altering their gene-expression program, and thus their phenotype (Leszczyniecka et al., 2001). One of the transcription factors primarily responsible for this change is the HIF-1 (Semenza, 2003). HIF-1 is a heterodimer that consists of a constitutively expressed $\beta$ subunit (HIF-1 $\beta$ or ARNT) and a catalytic a subunit (HIF-1a) (Harris, 2002; Semenza, 2003). At normoxia, HIF-1a is hydroxylated at specific proline residues by oxygen-dependent prolyl hydroxylases, leading to an interaction with the von Hippel-Lindau tumor suppressor protein (pVHL)/E3 ligase complex and subsequent ubiquitin mediated destruction (Maxwell et al., 1999; Ivan et al., 2001; Jaakkola et al., 2001). Under hypoxic conditions, HIF-1a escapes from hydroxylation and translocates to the nucleus, where it forms a complex with HIF-1 $\beta$ and the cAMP-responsive element binding protein (CREB)-binding protein (CBP) / p300 co-activator, binds to hypoxiaresponse elements and transcriptionally modulates target genes (Semenza, 2002). HIF-1 has been shown to play critical roles in tumor angiogenesis, glucose metabolism, invasion / metastasis, and response to radiation and chemotherapy (Moeller et al., 2005; Fulda\&Debatin, 2007; Lin et al., 2008; Rankin\&Giaccia, 2008; Yang et al., 2008). However, little is known about its possible role in the process of cellular differentiation in solid tumors.

Gliomas are the most common and malignant primary brain tumors in humans and are among the most hypoxic tumors known (DeAngelis, 2001; Rong et al., 2006). Glioblastoma multiforme, the highest-grade glioma, is characterized by large necrotic areas within the tumor mass, which correlates with enhanced resistance to therapy, increased invasiveness and a poor prognosis for the patient (Rong et al., 2006). In addition, malignant glioma cells could be induced to undergo differentiation towards their normal counterparts and thus serve as a faithful model to study molecular mechanisms underlying differentiation defects in solid tumors (Takanaga et al., 2004; Li et al., 2007).

In the present study, cobalt chloride and deferoxamine (DFO) are used to mimic an intratumoral mild hypoxia condition, and the data shows that differentiation induced by forskolin in rat C6 and primary cultured human malignant glioma cells is reversibly inhibited (Figure 11). Deletion of the endogenous HIF-1a gene restores the differentiation capacities, even in the presence of cobalt chloride (Figure 12a). In contrast, stabilization of HIF-1 with small interfering RNA (siRNA) against VHL, which leads to proteosomal degradation of HIF-1a, shows differentiation blockage similar to that induced by cobalt chloride (Figure 12b). Furthermore, inhibition of HIF-1a binding to its transcriptional coactivator $\mathrm{CBP} / \mathrm{p} 300$ by chetomin abolishes the differentiation-inhibitory effect of HIF-1 and attenuates tumor growth in combination with forskolin (Figure 13).

Analyses of human glioma tissues have suggested a strong correlation between the expression of HIF-1a and malignancy (World Health Organization grade). Expression of HIF-1a protein is found in all 95 samples (representative immunostaining images are shown in Figure 14a), and no obvious staining is observed in the five normal brain samples (a representative image is 

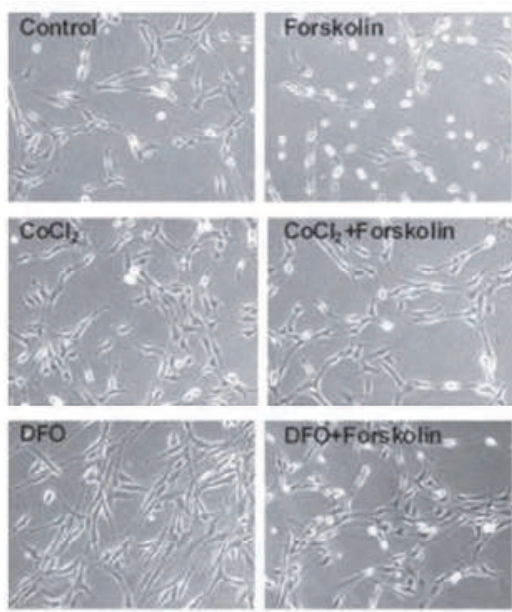

(a) Morphological transformation of $\mathrm{C} 6$ cells pretreated with $100 \mu \mathrm{M} \mathrm{CoCl}_{2}$ or $100 \mu \mathrm{M} \mathrm{DFO}$ for $2 \mathrm{~h}$ and then treated with $10 \mu \mathrm{M}$ forskolin for a further $24 \mathrm{~h}$. (Original magnification: $\times 200$.)

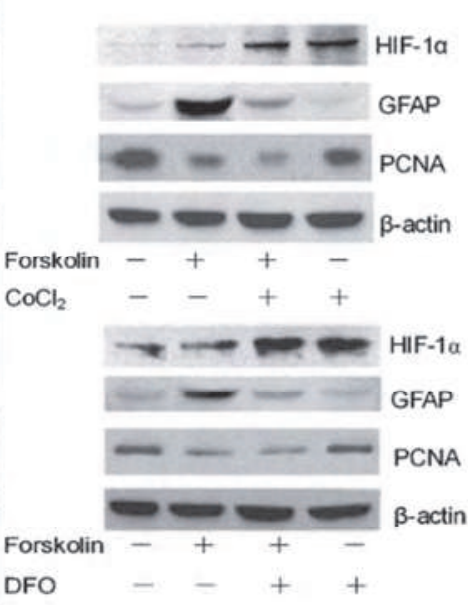

(b) HIF-1a, GFAP and PCNA expression of C6 cells pretreated with $100 \mu \mathrm{M} \mathrm{CoCl} 2$ or $100 \mu \mathrm{M}$ DFO for $2 \mathrm{~h}$ and then treated with $10 \mu \mathrm{M}$ forskolin for a further $24 \mathrm{~h}$.

Fig. 11. Cobalt chloride $\left(\mathrm{CoCl}_{2}\right)$ and DFO inhibit differentiation induced by forskolin in C6 glioma cells.
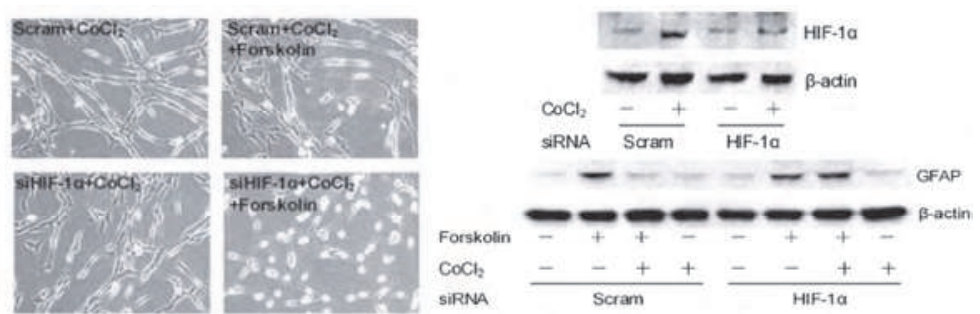

(a) Cobalt chloride $\left(\mathrm{COCl}_{2}\right.$ ) fails to induce HIF-1a accumulation in $\mathrm{C} 6$ cells transfected with siHIF-1a.
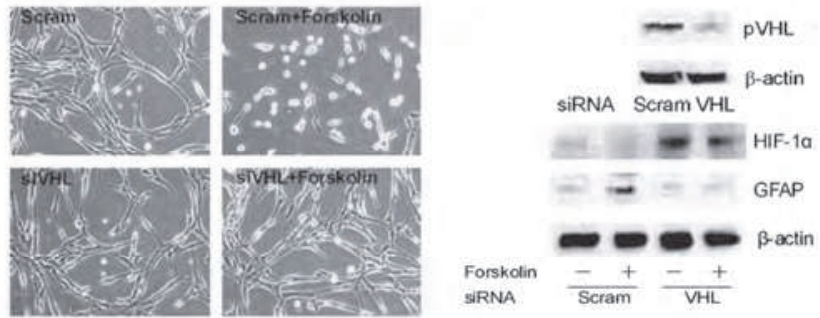

(b) VHL knockdown blocks differentiation of $\mathrm{C} 6$ cells.

Fig. 12. HIF-1a is required for the differentiation-inhibitory effect of cobalt chloride $\left(\mathrm{CoCl}_{2}\right)$ in C6 cells. 
shown in Figure 14a). Statistical evaluation reveals that the amount of HIF-1a is significantly increased in parallel with increasing glioma grade (Figure 14a). The percentage of HIF-1apositive cells in Grade I is $19.4 \%$, while one in Grade II, III and IV is 32.5\%, $46.1 \%$ and $70.5 \%$ respectively. Thus, HIF-1a is demonstrated to be broadly accumulated in glioma cells and its overexpression is correlated with glioma malignance grading, in other words, higher levels of expression of HIF-1a suggest a greater degree of differentiation defects.

Then, to test the generality of the inhibitory effects of HIF-1a, primary cultured human glioma cells are exposured to the differentiation agent forskolin. The result shows that forskolin also results in differentiated characteristics, of a stellar shape with filamentous processes and increased GFAP expression in the primary glioma cells (Figure 14b). However, co-incubation with cobalt chloride blocks the morphological alterations and increased the amount of GFAP induced by forskolin (Figure 14b). Quantitative analysis indicates that the percentage of GFAP-expressing cells is significantly up-regulated upon treatment with forskolin. Moreover, the up-regulation is reversed by cobalt chloride (Figure $14 \mathrm{~b})$. These results confirm the findings in C6 cells and, moreover, suggest a general correlation of HIF-1a activity with differentiation in malignant glioma cells.Taken together, HIF-1a negatively regulates the differentiation of malignant gliomas and provides new insights into the differentiation therapy by targeting the HIF-1a pathway in solid tumors.
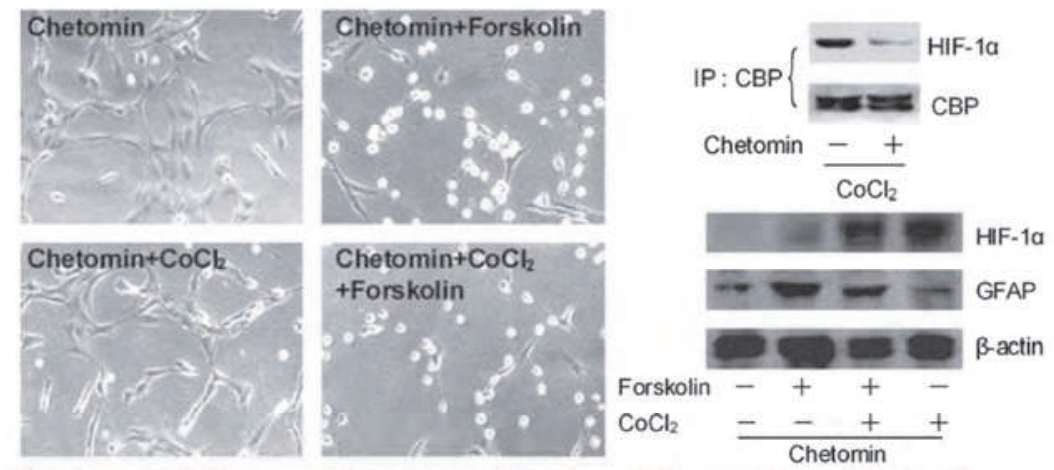

(a) Targeting HIF-1 by chetomin abolishes the differentiation-inhibitory effect of cobalt chloride

$\left(\mathrm{CoCl}_{2}\right)$ in vitro.
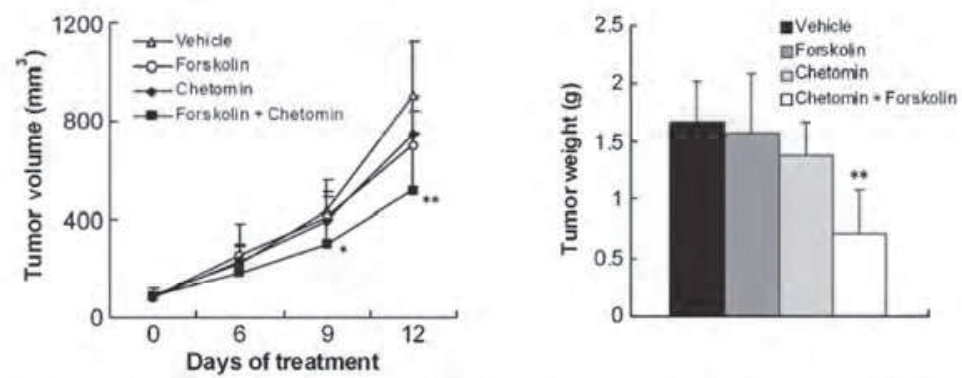

(b) Targeting HIF-1 by chetomin cooperates with forskolin to attenuate glioma growth in vivo.

Fig. 13. Chetomin abrogates the differentiation-inhibitory effect of cobalt chloride in vitro and combination of chetomin and forskolin attenuates tumor growth in vivo. 

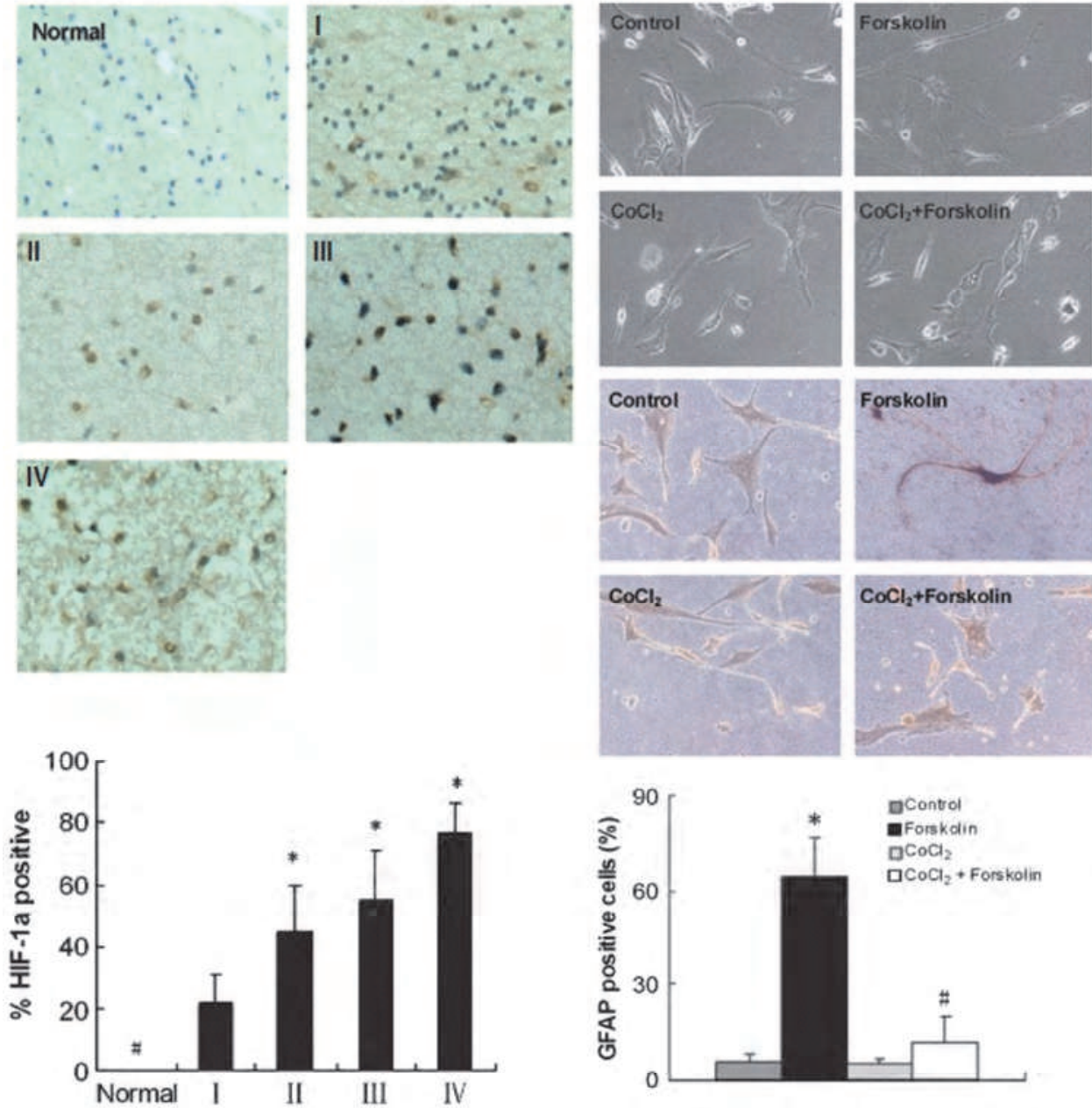

(a) HIF-1a expression increases with tumor

(b) HIF-1a blocks differentiation in primary human grade. malignant glioma cells.

Fig. 14. HIF-1a activity is generally correlated with differentiation in malignant gliomas.

\section{Conclusion}

Deviation from the tissuelineage-specific differentiation program is one of the fundamental aspects of tumorigenesis (Scott, 1997). The aberrantly differentiated cells show abnormal growth characteristics and distinct invasive and metastatic properties (Sell, 2004). Treating malignant tumors through the induction of cell differentiation has been an attractive concept, but clinical development of differentiation-inducing agents, especially for solid tumors, has been limited to date (Leszczyniecka et al., 2001). Several cell lines established 
from solid tumors are also reported to be differentiated by respective differentiationinducers in vitro (Chintharlapalli et al., 2004; El-Metwally et al., 2005; Li et al., 2007; Choi et al., 2009). However, this differentiation has not been verified in in vivo animal models or clinically, and there exists little convincing explanation for this finding.

Based on information mentioned above, cAMP/PKA signaling activators such as cholera toxin and foskolin is capable of inducing the differentiation of glioma cells highly expressing GSK-3 $\beta$, and overexpression of active GSK-3 $\beta$ can restore differentiation capacity of resistant glioma cells. In addition, HIF-1a is confirmed as a negative regulator of the differentiation in malignant gliomas, and targeting the HIF-1a pathway can potentiate the inhibitory effect of differentiation inducer in solid tumors. We have reasons to believe that all information above not only provide reasonable explanation in molecular mechanisms for the previous difficulty of differentiation therapy, but also will promote the development of differentiation therapy of glioma even solid tumor in future.

\section{Acknowledgment}

We thank Dr. Wei Yin, Yan Li, Huimin Lu, Songmin He, Minfeng Shu, Yijun Huang, Lijun Chen, Jun $\mathrm{Hu}$, Dong $\mathrm{Xu}$, Jun Xie and all other members of this laboratory for their excellent assistances to this work.

The project was supported by National Natural Science Foundation of China (No. 30830111).

\section{References}

Ammer, H. \& Schulz, R. (1997). Regulation of stimulatory adenylyl cyclase signaling during forskolin-induced differentiation of mouse neuroblastoma $x$ rat glioma (NG108-15) cells, Neurosci Lett 230(3): 143-146.

Arato-Ohshima, T. \& Sawa, H. (1999). Over-expression of cyclin D1 induces glioma invasion by increasing matrix metalloproteinase activity and cell motility, Int J Cancer 83(3): 387-392.

Bao, S., Wu, Q. \& McLendon, R. (2006). Glioma stem cells promote radioresistance by preferential activation of the DNA damage response, Nature 444(7120): 756-760.

Barton, K., Muthusamy, N. \& Chanyangam, M. (1996). Defective thymocyte proliferation and IL-2 production in transgenic mice expressing a dominant-negative form of CREB, Nature 379(6560): 81-85.

Brodsky, A., Davio, C. \& Shayo, C. (1998). Forskolin induces U937 cell line differentiation as a result of a sustained cAMP elevation, Eur J Pharmacol 350(1): 121-127.

Chintharlapalli, S., Smith, R. \& Samudio, I. (2004). 1,1 - Bis(3'-indolyl) - 1 - (psubstitutedphenyl) methanes induce peroxisome proliferator-activated receptor gamma-mediated growth inhibition, transactivation, and differentiation markers in colon cancer cells, Cancer Res 64(17): 5994-6001.

Choi, E., Oh, H. \& Wee, H. (2009). Eupatilin exhibits a novel anti-tumor activity through the induction of cell cycle arrest and differentiation of gastric carcinoma AGS cells, Differentiation 77(4): 412-423.

Cohen, P. \& Frame, S. (2001). The renaissance of GSK3, Nat Rev Mol Cell Biol 2(10): 769-776. 
Curran, W., Scott, C. \& Horton, J. (1993). Recursive partitioning analysis of prognostic factors in three Radiation Therapy Oncology Group malignant glioma trials, J Natl Cancer Inst 85(9): 704-710.

DeAngelis, L. (2001). Brain tumors, N Engl J Med 344(2): 114-123.

El-Metwally, T., Hussein, M. \& Pour, P. (2005). High concentrations of retinoids induce differentiation and late apoptosis in pancreatic cancer cells in vitro, Cancer Biol Ther 4(5): 602-611.

Fulda, S. \& Debatin, K. (2007). HIF-1-regulated glucose metabolism: a key to apoptosis resistance?, Cell Cycle 6(7): 790-792.

Goodman, L. \& Segreti, J. (1999). Infectious diarrhea, Dis Mon 45(7): 268-299.

Grimes, C. \& Jope, R. (2001). The multifaceted roles of glycogen synthase kinase 3beta in cellular signaling, Prog Neurobiol 65(4): 391-426.

Guerrant, R., Brunton, L. \& Schnaitman, T. (1974). Cyclic adenosine monophosphate and alteration of Chinese hamster ovary cell morphology: a rapid, sensitive in vitro assay for the enterotoxins of Vibrio cholerae and Escherichia coli, Infect Immun 10(2): 320-327.

Guerrant, R., Fang, G. \& Thielman, N. (1994). Role of platelet activating factor in the intestinal epithelial secretory and Chinese hamster ovary cell cytoskeletal responses to cholera toxin, Proc Natl Acad Sci U S A 91(20): 9655-9658.

Harris, A. (2002). Hypoxia--a key regulatory factor in tumour growth, Nat Rev Cancer 2(1): 38-47.

He, S., Zhu, W. \& Zhou, Y. (2011). Transcriptional and post-transcriptional downregulation of cyclin D1 contributes to C6 glioma cell differentiation induced by Forskolin, J Cell Biochem 112(5) : in press.

Helczynska, K., Kronblad, A. \& Jogi, A. (2003). Hypoxia promotes a dedifferentiated phenotype in ductal breast carcinoma in situ, Cancer Res 63(7): 1441-1444.

Hinoi, T., Yamamoto, H. \& Kishida, M. (2000). Complex formation of adenomatous polyposis coli gene product and axin facilitates glycogen synthase kinase- 3 betadependent phosphorylation of beta-catenin and down-regulates beta-catenin, J Biol Chem 275(44): 34399-34406.

Huang, M., Ye, Y. \& Chen, S. (1988). Use of all-trans retinoic acid in the treatment of acute promyelocytic leukemia, Blood 72(2): 567-572.

Impey, S., McCorkle, S. \& Cha-Molstad, H. (2004). Defining the CREB regulon: a genomewide analysis of transcription factor regulatory regions, Cell 119(7): 1041-1054.

Ivan, M., Kondo, K. \& Yang, H. (2001). HIFalpha targeted for VHL-mediated destruction by proline hydroxylation: implications for O2 sensing, Science 292(5516): 464-468.

Jaakkola, P., Mole, D. \& Tian, Y. (2001). Targeting of HIF-alpha to the von Hippel-Lindau ubiquitylation complex by O2-regulated prolyl hydroxylation, Science 292(5516): 468-472.

Jogi, A., Ora, I. \& Nilsson, H. (2002). Hypoxia alters gene expression in human neuroblastoma cells toward an immature and neural crest-like phenotype, Proc Natl Acad Sci U S A 99(10): 7021-7026.

Jope, R. \& Johnson, G. (2004). The glamour and gloom of glycogen synthase kinase-3, Trends Biochem Sci 29(2): 95-102. 
Kim, B., Kim, S. \& Kim, Y. (2004). Forskolin promotes astroglial differentiation of human central neurocytoma cells, Exp Mol Med 36(1): 52-56.

Kimura, M., Hidari, K. \& Suzuki, T. (2001). Engagement of endogenous ganglioside GM1a induces tyrosine phosphorylation involved in neuron-like differentiation of PC12 cells, Glycobiology 11(4): 335-343.

Kinjo, K., Kizaki, M. \& Muto, A. (2000). Arsenic trioxide (As2O3)-induced apoptosis and differentiation in retinoic acid-resistant acute promyelocytic leukemia model in hGM-CSF-producing transgenic SCID mice, Leukemia 14(3): 431-438.

Lamb, J., Ramaswamy, S. \& Ford, H. (2003). A mechanism of cyclin D1 action encoded in the patterns of gene expression in human cancer, Cell 114(3): 323-334.

Leszczyniecka, M., Roberts, T. \& Dent, P. (2001). Differentiation therapy of human cancer: basic science and clinical applications, Pharmacol Ther 90(2-3): 105-156.

Li, Y., Yin, W. \& Wang, X. (2007). Cholera toxin induces malignant glioma cell differentiation via the PKA/CREB pathway, Proc Natl Acad Sci U S A 104(33): 13438-13443.

Lin, M., Kuo, I. \& Chang, C. (2008). Involvement of hypoxia-inducing factor-1alphadependent plasminogen activator inhibitor-1 up-regulation in Cyr61/CCN1induced gastric cancer cell invasion, J Biol Chem 283(23): 15807-15815.

Lu, H., Li, Y. \& Shu, M. (2009). Hypoxia-inducible factor-1alpha blocks differentiation of malignant gliomas, FEBS J 276(24): 7291-7304.

Maeda, T., Watanabe, Y. \& Kunitomo, H. (1994). Cloning of the pka1 gene encoding the catalytic subunit of the cAMP-dependent protein kinase in Schizosaccharomyces pombe, J Biol Chem 269(13): 9632-9637.

Masco, D., Van de Walle, M. \& Spiegel, S. (1991). Interaction of ganglioside GM1 with the B subunit of cholera toxin modulates growth and differentiation of neuroblastoma N18 cells, J Neurosci 11(8): 2443-2452.

Masson, N., Hurst, H. \& Lee, K. (1993). Identification of proteins that interact with CREB during differentiation of F9 embryonal carcinoma cells, Nucleic Acids Res 21(11): 1163-1169.

Maxwell, P., Wiesener, M. \& Chang, G. (1999). The tumour suppressor protein VHL targets hypoxia-inducible factors for oxygen-dependent proteolysis, Nature 399(6733): 271275.

Moeller, B., Dreher, M. \& Rabbani, Z. (2005). Pleiotropic effects of HIF-1 blockade on tumor radiosensitivity, Cancer Cell 8(2): 99-110.

Moss, J. \& Vaughan, M. (1979). Activation of adenylate cyclase by choleragen, Annu Rev Biochem 48: 581-600.

Nurse, P. (2000). A long twentieth century of the cell cycle and beyond, Cell 100(1): 71-78.

Ougolkov, A., Bone, N. \& Fernandez-Zapico, M. (2007). Inhibition of glycogen synthase kinase-3 activity leads to epigenetic silencing of nuclear factor kappaB target genes and induction of apoptosis in chronic lymphocytic leukemia B cells, Blood 110(2): 735-742.

Ougolkov, A., Fernandez-Zapico, M. \& Savoy, D. (2005). Glycogen synthase kinase-3beta participates in nuclear factor kappaB-mediated gene transcription and cell survival in pancreatic cancer cells, Cancer Res 65(6): 2076-2081. 
Pouyssegur, J., Dayan, F. \& Mazure, N. (2006). Hypoxia signalling in cancer and approaches to enforce tumour regression, Nature 441(7092): 437-443.

Rankin, E. \& Giaccia, A. (2008). The role of hypoxia-inducible factors in tumorigenesis, Cell Death Differ 15(4): 678-685.

Rask, K., Nilsson, A. \& Brannstrom, M. (2003). Wnt-signalling pathway in ovarian epithelial tumours: increased expression of beta-catenin and GSK3beta, Br J Cancer 89(7): 1298-1304.

Rong, Y., Durden, D. \& Van Meir, E. (2006). 'Pseudopalisading' necrosis in glioblastoma: a familiar morphologic feature that links vascular pathology, hypoxia, and angiogenesis, J Neuropathol Exp Neurol 65(6): 529-539.

Roymans, D., Vissenberg, K. \& De Jonghe, C. (2001). Phosphatidylinositol 3-kinase activity is required for the expression of glial fibrillary acidic protein upon cAMP-dependent induction of differentiation in rat C6 glioma, J Neurochem 76(2): 610-618.

Sato, K., Suematsu, A. \& Nakashima, T. (2006). Regulation of osteoclast differentiation and function by the CaMK-CREB pathway, Nat Med 12(12): 1410-1416.

Schluter, C., Duchrow, M. \& Wohlenberg, C. (1993). The cell proliferation-associated antigen of antibody Ki-67: a very large, ubiquitous nuclear protein with numerous repeated elements, representing a new kind of cell cycle-maintaining proteins, J Cell Biol 123(3): 513-522.

Scott, R. (1997). Differentiation, differentiation/gene therapy and cancer, Pharmacol Ther 73(1): 51-65.

Sell, S. (2004). Stem cell origin of cancer and differentiation therapy, Crit Rev Oncol Hematol 51(1): 1-28.

Semenza, G. (2002). Signal transduction to hypoxia-inducible factor 1, Biochem Pharmacol 64(5-6): 993-998.

Semenza, G. (2003). Targeting HIF-1 for cancer therapy, Nat Rev Cancer 3(10): 721-732.

Shachaf, C., Kopelman, A. \& Arvanitis, C. (2004). MYC inactivation uncovers pluripotent differentiation and tumour dormancy in hepatocellular cancer, Nature 431(7012): 1112-1117.

Shen, Z., Chen, G. \& Ni, J. (1997). Use of arsenic trioxide (As2O3) in the treatment of acute promyelocytic leukemia (APL): II. Clinical efficacy and pharmacokinetics in relapsed patients, Blood 89(9): 3354-3360.

Sherr, C. \& Roberts, J. (1999). CDK inhibitors: positive and negative regulators of G1-phase progression, Genes Dev 13(12): 1501-1512.

Shu, M., Zhou, Y. \& Zhu, W. (2011). Activation of a pro-survival pathway IL-6 / JAK2 / STAT3 contributes to glial fibrillary acidic protein induction during the cholera toxin-induced differentiation of C6 malignant glioma cells, Mol Oncol 219: 1-8.

Takanaga, H., Yoshitake, T. \& Hara, S. (2004). cAMP-induced astrocytic differentiation of C6 glioma cells is mediated by autocrine interleukin-6, J Biol Chem 279(15): 1544115447.

Van Kolen, K. \& Slegers, H. (2004). P2Y12 receptor stimulation inhibits beta-adrenergic receptor-induced differentiation by reversing the cyclic AMP-dependent inhibition of protein kinase B, J Neurochem 89(2): 442-453.

Walsh, D. \& Van Patten, S. (1994). Multiple pathway signal transduction by the cAMPdependent protein kinase, FASEB J 8(15): 1227-1236. 
Wang, Z. \& Chen, Z. (2000). Differentiation and apoptosis induction therapy in acute promyelocytic leukaemia, Lancet Oncol 1: 101-106.

Woodgett, J. (1991). cDNA cloning and properties of glycogen synthase kinase-3, Methods Enzymol 200: 564-577.

Yang, M., Wu, M. \& Chiou, S. (2008). Direct regulation of TWIST by HIF-1alpha promotes metastasis, Nat Cell Biol 10(3): 295-305.

Yiu, G. \& He, Z. (2006). Glial inhibition of CNS axon regeneration, Nat Rev Neurosci 7(8): 617-627. 


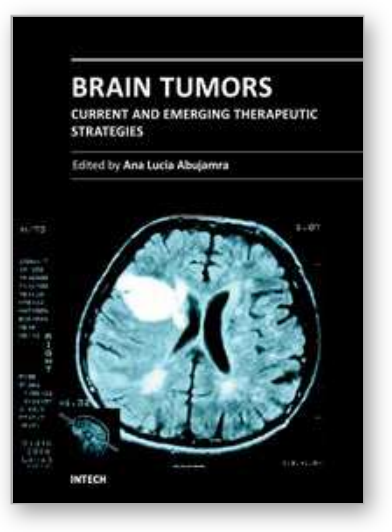

\author{
Brain Tumors - Current and Emerging Therapeutic Strategies \\ Edited by Dr. Ana Lucia Abujamra
}

ISBN 978-953-307-588-4

Hard cover, 422 pages

Publisher InTech

Published online 23, August, 2011

Published in print edition August, 2011

Brain Tumors: Current and Emerging Therapeutic Strategies focuses on tumor models, the molecular mechanisms involved in the pathogenesis of this disease, and on the new diagnostic and treatment strategies utilized to stage and treat this malignancy. A special section on immunotherapy and gene therapy provides the most up-to-date information on the pre-clinical and clinical advances of this therapeutic venue. Each chapter in Brain Tumors: Current and Emerging Therapeutic Strategies is authored by international experts with extensive experience in the areas covered.

\title{
How to reference
}

In order to correctly reference this scholarly work, feel free to copy and paste the following:

Wenbo Zhu and Guangmei Yan (2011). The Molecular Mechanism for Differentiation Therapy of Malignant Glioma, Brain Tumors - Current and Emerging Therapeutic Strategies, Dr. Ana Lucia Abujamra (Ed.), ISBN: 978-953-307-588-4, InTech, Available from: http://www.intechopen.com/books/brain-tumors-current-andemerging-therapeutic-strategies/the-molecular-mechanism-for-differentiation-therapy-of-malignant-glioma

\section{INTECH}

open science | open minds

\section{InTech Europe}

University Campus STeP Ri

Slavka Krautzeka 83/A

51000 Rijeka, Croatia

Phone: +385 (51) 770447

Fax: +385 (51) 686166

www.intechopen.com

\section{InTech China}

Unit 405, Office Block, Hotel Equatorial Shanghai

No.65, Yan An Road (West), Shanghai, 200040, China

中国上海市延安西路65号上海国际贵都大饭店办公楼 405 单元

Phone: +86-21-62489820

Fax: +86-21-62489821 
(C) 2011 The Author(s). Licensee IntechOpen. This chapter is distributed under the terms of the Creative Commons Attribution-NonCommercialShareAlike-3.0 License, which permits use, distribution and reproduction for non-commercial purposes, provided the original is properly cited and derivative works building on this content are distributed under the same license. 